\title{
Ballistic Efficiency of Multilayered Armor Systems with Sisal Fiber Polyester Composites
}

\author{
Fábio de Oliveira Braga ${ }^{a, b}$, Lucas Tedesco Bolzan ${ }^{a}$, Flávio James Humberto Tommasini Vieira Ramos ${ }^{a}$, \\ Sergio Neves Monteiro ${ }^{a}$ Édio Pereira Lima Jr. ${ }^{a}$, Luis Carlos da Silva ${ }^{a}$ \\ ${ }^{a}$ Instituto Militar de Engenharia - IME, Seção de Engenharia Mecânica e de Materiais, Praça General \\ Tibúrcio, 80, Praia Vermelha, Urca, CEP 22290-270, Rio de Janeiro, RJ, Brazil \\ ${ }^{b}$ Serviço Nacional de Aprendizagem Industrial do Estado do Rio de Janeiro - SENAI/RJ, Faculdade \\ SENAI Rio, Rua Mariz e Barros, 678, CEP 20270-003, Tijuca, RJ, Brazil
}

Received: November 10, 2017; Accepted: December 04, 2017

\begin{abstract}
The urban violence and the different types of global armed conflicts demand efficient protective systems against high energy ammunition. Multilayered Armor Systems (MAS) provide efficient protection by making use of lighter and more efficient materials. A typical MAS may be composed of three layers: a front ceramic followed by a composite, backed by a ductile metal. Polymer composites reinforced with natural fibers have proven to be effective second layers, being also lighter, low-cost and environmentally friendly as compared to conventional composites like Kevlar ${ }^{\mathrm{TM}}$. The present work evaluates MAS using as second layer polyester composites reinforced with 10, 20, and $30 \mathrm{vol}$. \% of sisal fibers. Ballistic tests were performed using class III $7.62 \times 51 \mathrm{~mm}$ ammunition, based on the NIJ 0101.06 backface signature methodology. Both the 30 vol.\% sisal fiber composite and the conventional aramid laminates were equally efficient in terms of MAS second layer. The explanation might be the similar capacity of the different composites to retain the fragments generated by the interaction of the projectile with the front ceramic, independently of the percentage of sisal fibers.
\end{abstract}

Keywords: Natural fiber composites, sisal fibers, multilayered armor, ballistic test.

\section{Introduction}

The ever expanding urban and war armed conflicts demand efficient personal armor protective systems. For high impact energy ammunitions, such as $7.62 \mathrm{~mm}$, one single material armor is not efficient enough to either stop the projectile or prevent a lethal trauma to the wearer ${ }^{1-2}$. For this type of ammunition, light and efficient solutions have been developed, in the form of Multilayered Armor Systems (MAS), also called Composite Armor ${ }^{3-6}$. These systems can be used for ballistic protection in various applications, including an individual personal vest and equipment, like armored vehicles. The MAS provide safety by making use of light and efficient materials disposed in several layers, usually three: a frontal ceramic layer, a high performance fiber fabric or composite second layer, and a ductile metal back layer ${ }^{3,6}$.

Currently, natural fiber reinforced composites are being extensively studied as possible MAS second layer in both ballistic $^{7-11}$ and non-ballistic ${ }^{12}$ applications, due to their good performance associated with other advantages over conventional composites like Kevlar ${ }^{\mathrm{TM}}$, such as being lighter, cheaper and environmentally friendly.

The front layer of the MAS is usually made of a hard ceramic material, which is able of eroding and deforming

*e-mail: fabio_obraga@yahoo.com.br the sharp tip of a high speed projectile like the class III 7.62 $\mathrm{mm}(\sim 850 \mathrm{~m} / \mathrm{s})$. Ceramics are also efficient to absorb the projectile kinetic energy by an intrinsic spalling mechanism. For the second layer, laminates or composites made of polymer fibers are used. The second layer of the MAS deserves special attention, because it defines whether the pulse of pressure that returns to the front layer will be tensile or compressive ${ }^{13}$. The lighter the material in the second layer, the lower is its shock impedance and so the pulse might return as a tensile wave. In this case the ceramic tile will entirely be fragmented, absorbing a greater amount of the projectile energy ${ }^{13}$. Synthetic fiber fabrics such as aramid (Kevlar ${ }^{\mathrm{TM}}$ or Twaron $\left.{ }^{\mathrm{TM}}\right)^{14}$ and ultra-high molecular weight polyethylene (Dyneema ${ }^{\mathrm{TM}}$ of Spectra $\left.^{\mathrm{TM}}\right)^{15}$ have been conventionally used as MAS second layers. However, polymeric composites reinforced with natural fibers were found to be more interesting alternative, due to their low density and low cost, as well as high tensile and impact strength ${ }^{7-11}$. Among the natural fibers, those fibers extracted from the leaves of the Agave sisalana plant, called sisal, show desirable properties associated with low density $\left(1.26-1.50 \mathrm{~g} / \mathrm{cm}^{3}\right)$, high strength $(287-913 \mathrm{MPa})$ and high elastic modulus $(9-28 \mathrm{GPa})^{16}$. The application of sisal fiber epoxy composite has been shown as promising MAS second layer ${ }^{11}$. Indeed, it contributes to prevent the lethal trauma in the human body, based on the International Standard (NIJ0101-06) methodology ${ }^{17}$, which takes into consideration the safety depth of indentation made in a clay witness positioned 
behind the MAS. According to the standard ${ }^{17}$, the indentation, also known as backface signature, should be smaller than 1.73 inch (44 mm), in order to be considered efficient

Rohen and co-workers ${ }^{11}$ conducted a preliminary study on 30 vol. \% of sisal fiber-reinforced epoxy composite as MAS second layer. In the present work, sisal fiber composites were studied for the same application, using not only different volumetric percentages but also a low cost polyester matrix. Therefore, the objective of this work was to evaluate the ballistic behavior of $0,10,20$ and 30 vol.\% sisal fiber-reinforced polyester composites as a MAS second layer subjected to $7.62 \mathrm{~mm}$ ballistic impact. It was also presented an economical analysis.

\section{Materials and Methods}

The MAS investigated in the present work was composed of a front hexagon-shaped $(30 \mathrm{~mm}$ in edge and $10 \mathrm{~mm}$ in thickness) $\mathrm{Al}_{2} \mathrm{O}_{3}-4 \% \mathrm{Nb}_{2} \mathrm{O}_{5}$ ceramic tile. A rectangular plate $(120 \times 150 \times 10 \mathrm{~mm})$ was used as second layer of polyester composites reinforced with continuous sisal fibers. A back layer of $5052 \mathrm{H} 34$ aluminum alloy, also as rectangular plate (120x150x5 mm), finished the MAS. The layers were bonded together using a polyurethane adhesive.

The ceramic powders, $\mathrm{Al}_{2} \mathrm{O}_{3}$ (acquired from Treibacher Schleifmittel) and $\mathrm{Nb}_{2} \mathrm{O}_{5}$ (acquired from the Companhia Brasileira de Metalurgia e Mineração - CBMM) were mixed in a 4 wt. $\% \mathrm{Nb}_{2} \mathrm{O}_{5}$ proportion. The mixture was then ball milled in aqueous suspension, dried at $60^{\circ} \mathrm{C}$ for 48 hours, sifted until the 0.355 screen, cold pressed at $30 \mathrm{MPa}$ and sintered at $1400^{\circ} \mathrm{C}$ for 3 hours.

For the composite production, an orthophtalic polyester resin hardened with $0.5 \mathrm{wt} . \%$ of methyl ethyl ketone, both supplied by the Resinpoxy, Brazil, was used as polymeric matrix. The sisal fibers were supplied by the Sisalsul, Brazil, in the form of bundles. The fibers were manually cleaned, cut and dried at $60^{\circ} \mathrm{C}$ for $24 \mathrm{~h}$ for the production of composites. Continuous and aligned fiber composite plates (120 x 150 $\mathrm{x} 10 \mathrm{~mm}$ ) were prepared by compression molding, at room temperature $\left(25^{\circ} \mathrm{C}\right)$, in the volumetric fractions of 10, 20 and 30 vol.\%. Plain polyester plates were similarly prepared. The fibers were carefully positioned in the mold. After adding the resin with hardener, the mixture was kept under a pressure of $5 \mathrm{MPa}$ for 24 hours. Third MAS layer of the $5052 \mathrm{H} 34$ aluminum alloy, with same $120 \times 150 \times 10 \mathrm{~mm}$ dimensions, were cut from sheets supplied by sheets were acquired from the Metalak Metais, Brazil.

Ballistic tests were performed with NATO $7.62 \mathrm{x}$ $51 \mathrm{~mm}$ military ammunition, following the NIJ 0101.06 (2008) procedures ${ }^{17}$. This means that the MAS target was positioned in front of a Roma Plastilina type of clay witness that simulates the consistency of the human body, 15 meters away from the shooting device. The experimental arrangement is shown in Fig. 1a and a real MAS mounted for the test in
Fig. 1b. The shooting device was a model B290 gun barrel with laser sight (Fig. 1c), produced by HPI - High Pressure Instrumentation, available at the Brazilian Army Assessment Center (CAEx), located in the Marambaia peninsula, Rio de Janeiro, Brazil. The bullet velocity was measured by both optical barriers and a model SL-520P Weibel doppler radar. The velocity was kept in the $847 \pm 9.1 \mathrm{~m} / \mathrm{s}$ range, measured $2.5 \mathrm{~m}$ before the target, as specified by the NIJ standard ${ }^{17}$. The indentation imprinted by the armor in the clay witness after the impact (backface signature) was measured by laser sensor and taken as a measure of the ballistic performance. The standard ${ }^{17}$ specifies that the mean indentation be no deeper than 1.73 inch $(44 \mathrm{~mm})$. Figure 1d depicts a measurement of the indentation after the impact.

Ten samples of each group were tested and the data were statistically treated by the Weibull analysis, which gave information about the indentation distribution of probability ${ }^{18}$. The Weibull's density of probability function is given by Eq. 1 .

$$
F(x)=1-\exp \left[-\left(\frac{x}{\theta}\right)^{\beta}\right]
$$

Where $x$ is the value assumed by the random variable; $\theta$ is the scale parameter and $\beta$ is the shape parameter, also known as Weibull modulus.

Impedance matching of the impact wave propagation in the MAS front ceramic and reflection at the backing plate was evaluated to compare the efficiency of the sisal composites. Literature data on conventional Kevlar ${ }^{\mathrm{TM}}$ laminates were also consulted $^{19}$. According to Meyers ${ }^{13}$, the pressure generated in the interface between layers during shock can be calculated by the following equation:

$$
P=\rho_{0} U_{S} U_{P}=Z U_{P}
$$

Where $\rho_{o}$ is the density of the material; $U_{S}$ is the shock wave velocity and $U_{\mathrm{P}}$ is the particle velocity. The product $Z$ $={ }_{\rho o} U_{S}$ in Eq. 2 is known as shock impedance of the material. In the present work, the value of $\mathrm{Z}$ was calculated by the impedance matching technique ${ }^{13}$ applied to the ceramic/second layer interface. This method basically finds the solution to the conservation equations (mass, momentum and energy) together with the equation of state of the material ${ }^{13}$.

In addition to the MAS ballistic tests, the materials that compose the layers were individually tested, as shown in Fig. 2 , by shooting the single layer specimens mounted in front of a hollow aluminum block. In this case, it was expected perforation in all tests, so it was necessary another methodology for comparing the materials, based on residual velocity.

The bullet velocity was measured by the Doppler radar before and after (residual) the impact. Using this data, the absorbed kinetic energy could be calculated according to the Eq.3, and used to compare the individual ballistic behavior of the materials. 

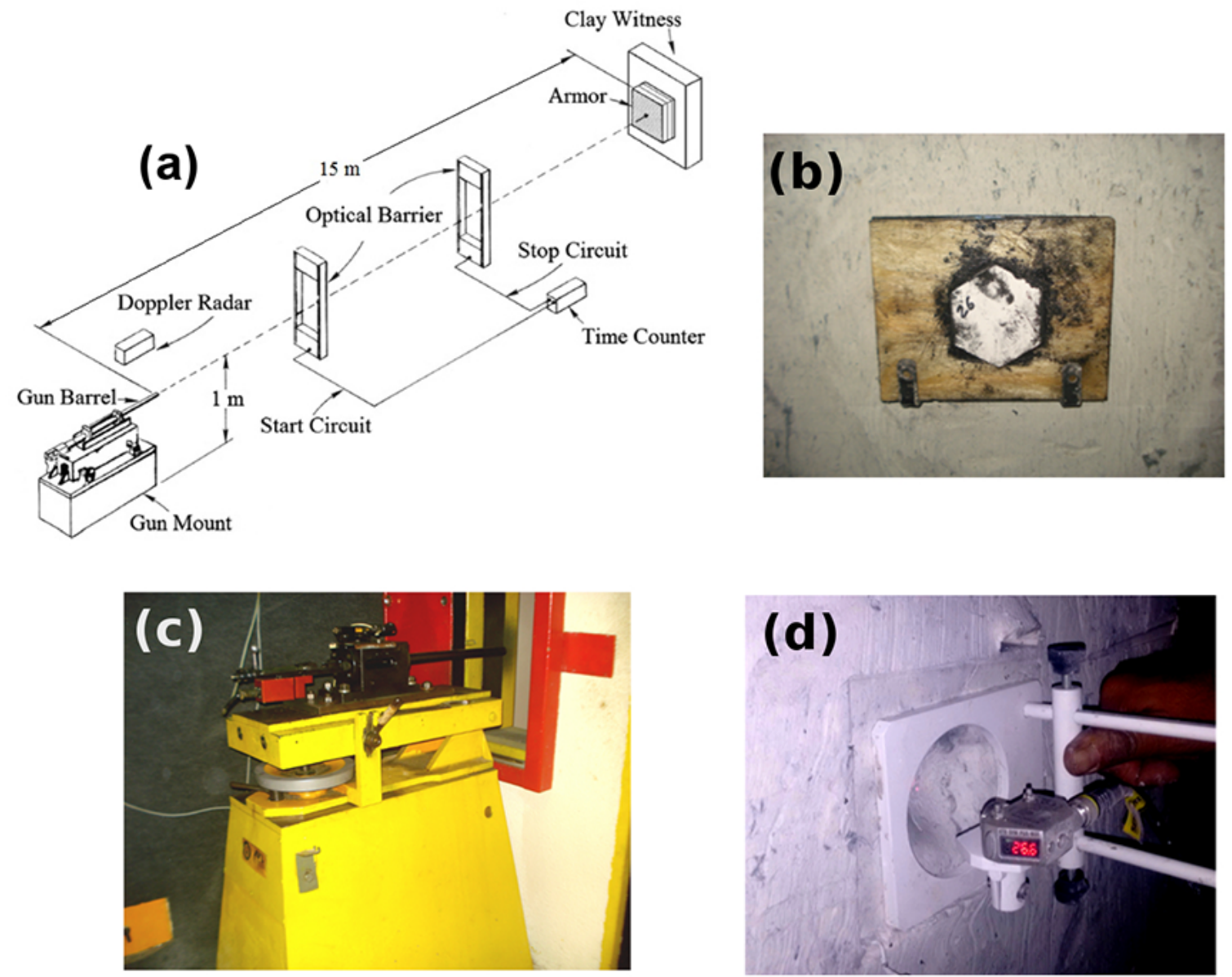

Figure 1. Ballistic test: (a) Schematic diagram with the experimental arrangement; (b) MAS positioned in front of the clay witness; (c) Gun barrel with laser sight; (d) Measurement of the indentation after the impact.

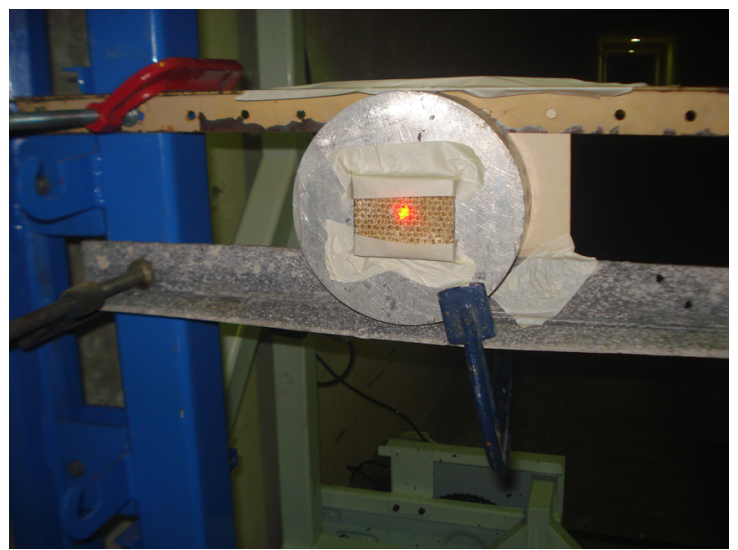

Figure 2. Sisal fiber composite sample mounted for the residual velocity test.

$$
E_{a b s}=m\left(\nu_{i}^{2}-\nu_{r}^{2}\right) / 2
$$

Where $m$ is the mass of the bullet; $v_{\mathrm{i}}$ is the velocity of the bullet immediately before impacting the target; $v_{\mathrm{r}}$ its residual velocity immediately after impacting the target.
After the MAS ballistic tests, fragments of the samples were collected and analyzed by scanning electron microscopy (SEM), in a model Quanta FEG FEI equipment, available at IME.

\section{Results and Discussion}

In the ballistic tests, none of the MAS were perforated, as can be seen in Fig. 3. Since the projectile was stopped, its kinetic energy was dissipated inside the MAS and partially transmitted to the clay witness, causing the indentation. Table 1 presents the mean values of indentation depths in the clay witness for the different MAS. All indentation values were below $44 \mathrm{~mm}$, and thus all tested MAS can be considered efficient according to the NIJ 0101.06 standard $^{17}$. Besides that, since the intervals of deviation intercept each other, the values for the different MAS can be considered statistically equal.

Another aspect of Fig. 3 is the rupture behavior of the materials in the MAS. One may note that all ceramic front tiles were totally fragmented. This was expected, since ceramic spalling is the main mechanism of the projectile's energy 

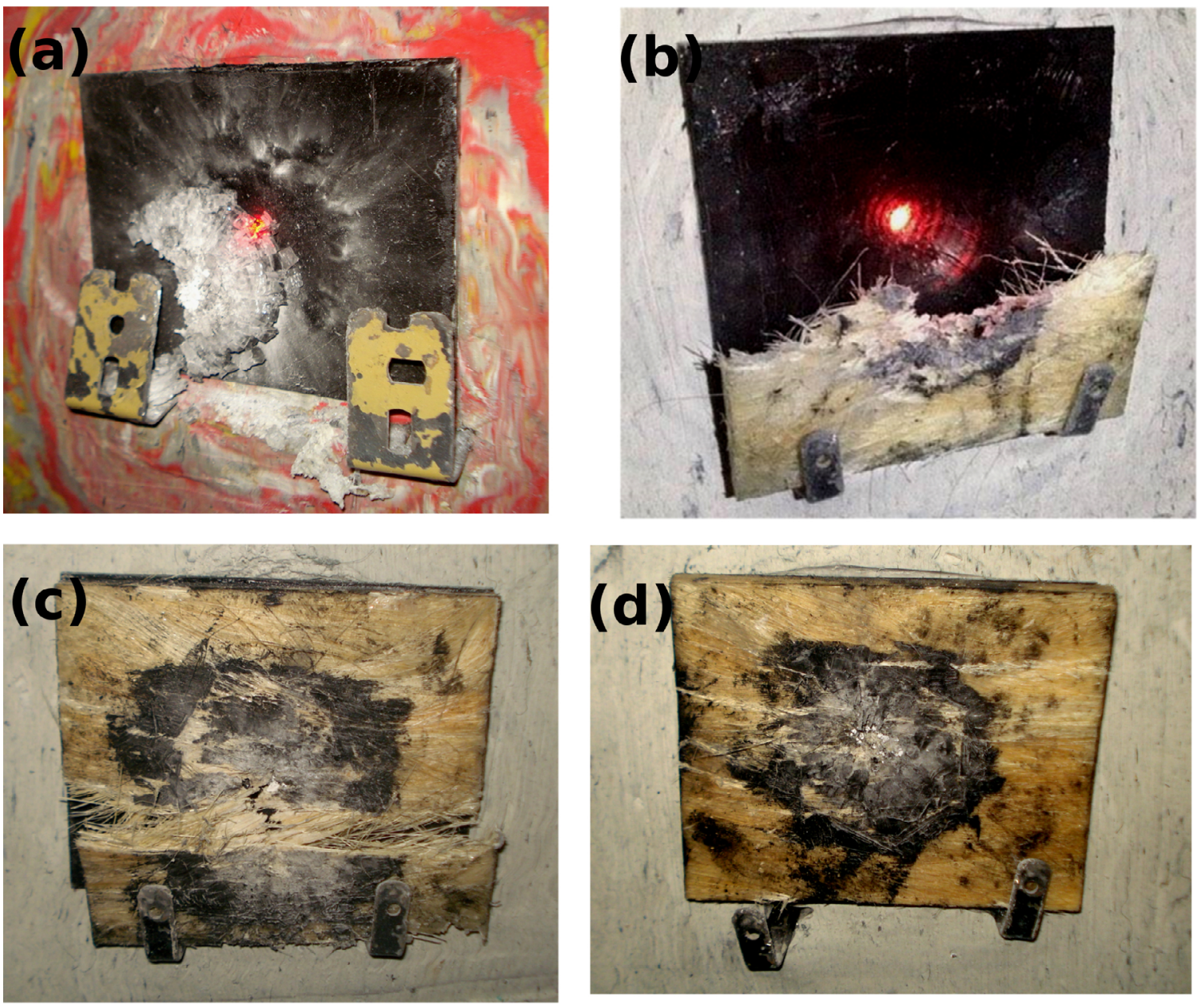

Figure 3. View of the MAS target after the ballistic test, with second layer of (a) neat polyester resin; (b) 10 vol.\% sisal fiber polyester composite; (c) 20 vol.\% sisal fiber polyester composite; (d) 30 vol.\% sisal fiber polyester composite.

Table 1. Average depth of indentation in the clay witness backing different multilayered armors.

\begin{tabular}{ccc}
\hline Intermediate material layer & Average depth of indentation $(\mathrm{mm})$ & Reference \\
\hline Polyester-30 vol.\% Sisal Fiber & $22 \pm 3$ & $\mathrm{PW}^{*}$ \\
Polyester-20 vol.\% Sisal Fiber & $26 \pm 4$ & $\mathrm{PW}^{*}$ \\
Polyester-10 vol.\% Sisal Fiber & $26 \pm 2$ & $\mathrm{PW}^{*}$ \\
Neat polyester resin & $23 \pm 3$ & Monteiro et al., 2015 \\
Aramid fabric laminates & $23 \pm 3$ & Monteiro et al., 2015 \\
\hline
\end{tabular}

*Present work.

absorption $^{6}$. That is the reason why the front ceramic should be backed by other ductile material. According to the NIJ standard ${ }^{17}$, a personal armor should be tested by a sequence of six threat rounds with each impact no closer to a prior impact than $51 \mathrm{~mm}$. To achieve a multi-hit protection, therefore, the ceramic layer is commonly arranged in a close-packed mosaic of tiles (pieces), with lateral sides of less than $51 \mathrm{~mm}$. The second layer, however, should maintain its integrity to keep the ceramic tiles around the impact in their positions. In the present work, it was noticed an improvement of the second layer's integrity as the percentage of sisal fibers increased. Indeed, neat polyester resin was completely fragmented after the ballistic impact, Fig. $3 \mathrm{a}$, the 10 vol. $\%$ and 20 vol. $\%$ composites, Fig. $3 \mathrm{~b}$ and $3 \mathrm{c}$ respectively, were partially fragmented. As for the 30 vol. \% composite, Fig. 3d, its whole integrity was maintained after the impact. This can be attributed to the improved impact strength of the material in the intermediate layer as the fiber content increases.

The results for the different MAS in Table 1 were very close to each other, even though their macroscopic behaviors 

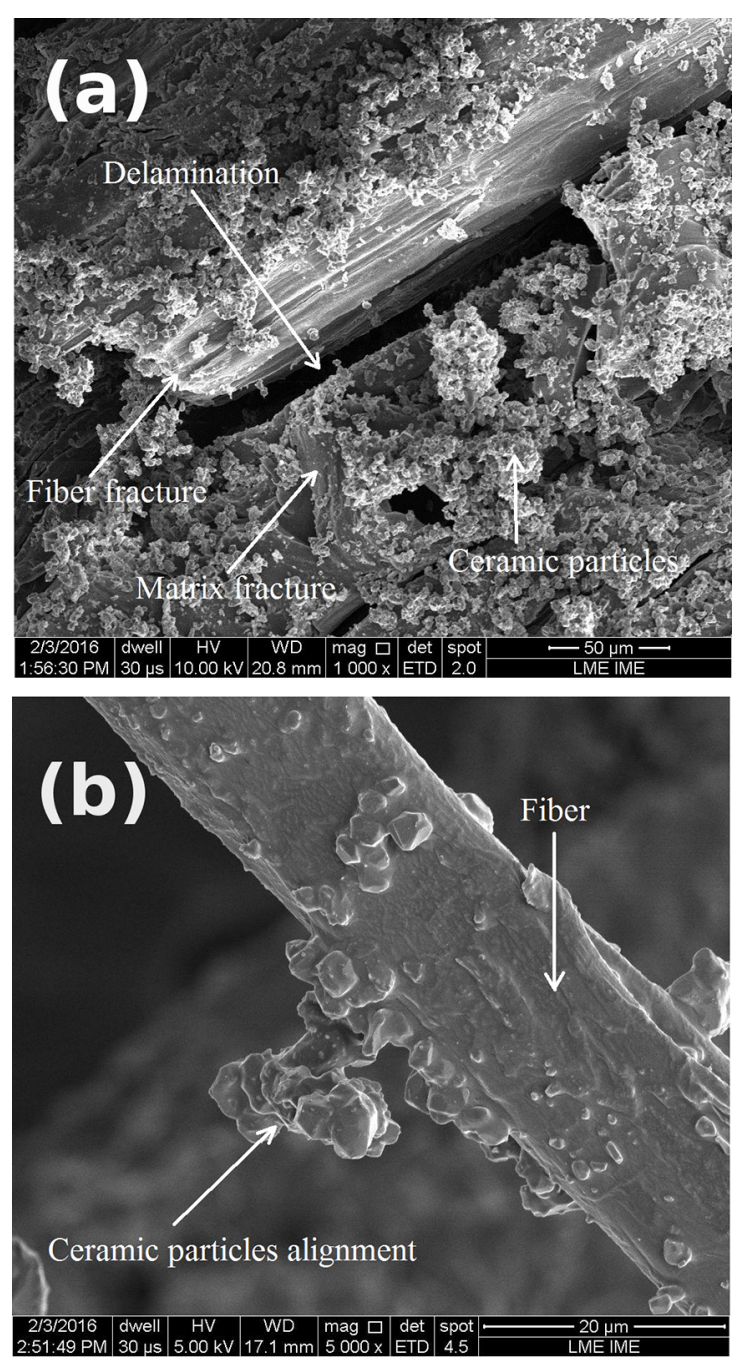

Figure 4. SEM micrographs of the fracture surface of the composites covered with ceramic fragments: (a) 1000x; (b) 5000x.

were dissimilar. It has been previously found ${ }^{6}$ that one of the main contributions that the second layer exerts for improving the MAS performance is the ability of collecting the fragments of both the projectile and the front ceramic layer. This is accomplished by mechanisms of mechanical

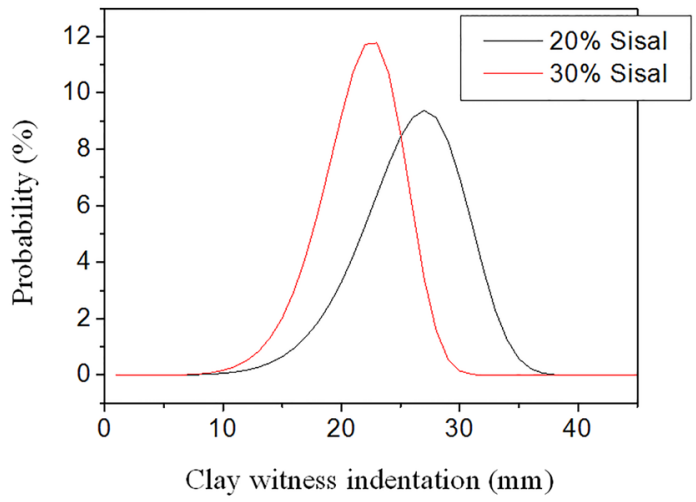

Figure 5. Weibull density of probability function for the depths of indentation for the MAS with 20 and 30 vol. $\%$ sisal fiber composites.

incrustation, as well as attraction due to the presence of Van der Waals forces and short-living surface static charges ${ }^{6}$. Figure 4 shows SEM micrographs illustrating the fracture features. The explanation for the similarity between depths of indentation in the clay witness (Table 1) might be the similar capacity of the different composites, as well as the neat polyester resin and $\mathrm{Kevlar}^{\mathrm{TM}}$, to retain the fragments generated by the interaction of the projectile with the front ceramics.

According to the impedance matching analysis, Table 2 , it would be expected that the lower the shock impedance of the second layer, the smaller the indentation in the clay witness. The reason is that a reflected tensile wave with higher amplitude would be generated, and thus fragmenting more effectively the ceramic tile. In this case, the MAS with neat polyester resin in the second layer should present the best results and $30 \mathrm{vol} . \%$ sisal fiber composites the worst. However, since the results were very close to each other, with no apparent trend, one might think that the trauma protection provided by the second layer is not so sensitive to its shock impedance. In other words, differences of $1.10^{6} \mathrm{~kg} / \mathrm{m}^{2} . \mathrm{s}$ might be too small to affect the trauma in the clay witness.

Another failure mechanism of the composites that can be observed in Figure 3(b-d) is the delamination, which is the fracture along the interface between both phases: matrix and

Table 2. Calculated parameters for the impedance matching analysis (Eq.2).

\begin{tabular}{cccccc}
\hline Second layer at $\mathrm{Al}_{2} \mathrm{O}_{3}$ ceramic interface & $\boldsymbol{U p}(\mathrm{km} / \mathrm{s})$ & $\boldsymbol{P}(\mathrm{GPa})$ & $\boldsymbol{U s}(\mathrm{km} / \mathrm{s})$ & $\boldsymbol{Z}\left(10^{6} \mathrm{~kg} / \mathrm{m}^{2} . \mathrm{s}\right)$ & $\mathrm{Reference}$ \\
\hline Polyester-30 vol.\% Sisal Fiber & 0.77 & 2.3 & 2.5 & 3.0 & $\mathrm{PW}^{*}$ \\
Polyester-20 vol.\% Sisal Fiber & 0.77 & 2.1 & 2.2 & 2.7 & $\mathrm{PW}$ \\
Polyester-10 vol.\% Sisal Fiber & 0.79 & 1.8 & 2.0 & 2.3 & $\mathrm{PW}$ \\
Neat polyester resin & 0.79 & 1.6 & 1.6 & 2.0 & $\mathrm{PW}$ \\
\hline
\end{tabular}

*Present work.

Table 3. Weibull statistical parameters for ballistic tests with MAS having different second layers

\begin{tabular}{cccc}
\hline Intermediate material layer & Weibull modulus $(\beta)$ & Scale parameter $(\theta)$ & Correlation coeficient $\left(\mathrm{R}^{2}\right)$ \\
\hline Polyester-30 vol.\% Sisal Fiber & 7.357 & 23.00 & 0.9642 \\
Polyester-20 vol.\% Sisal Fiber & 6.969 & 27.63 & 0.9199 \\
\hline
\end{tabular}


Table 4. Impact and residual velocities with internally dissipated energy in individually ballistic tested MAS components.

\begin{tabular}{cccccc}
\hline MAS component & $\boldsymbol{v}_{\mathrm{i}}(\mathrm{m} / \mathrm{s})$ & $\boldsymbol{v}_{\mathrm{r}}(\mathrm{m} / \mathrm{s})$ & $\mathrm{E}_{\mathrm{abs}}(\mathrm{J})$ & $\mathrm{E}_{\mathrm{abs}}(\%)$ & Reference \\
\hline Polyester-30 vol.\% Sisal Fiber & $845 \pm 6$ & $828 \pm 6$ & 139 & 4.0 & $\mathrm{PW}^{*}$ \\
Polyester-20 vol.\% Sisal Fiber & $834 \pm 13$ & $819 \pm 13$ & 116 & 3.4 & $\mathrm{PW}^{*}$ \\
5052 H34 aluminum sheet & $860 \pm 6$ & $832 \pm 9$ & 234 & 6.5 & $\mathrm{PW}^{*}$ \\
$\mathrm{Al}_{2} \mathrm{O}_{3}$ ceramic & $848 \pm 6$ & $567 \pm 43$ & 1920 & 55.3 & Monteiro et al., 2015 \\
Aramid fabric laminates & $848 \pm 6$ & $841 \pm 7$ & $58 \pm 29$ & 1.7 & Monteiro et al., 2015 \\
\hline
\end{tabular}

*Present work.

Table 5. Evaluation of weight and cost of the different multilayered armor components.

\begin{tabular}{|c|c|c|c|c|c|}
\hline Armor component & Volume $\left(\mathrm{cm}^{3}\right)$ & $\begin{array}{l}\text { Density } \\
\left(\mathrm{g} / \mathrm{cm}^{3}\right)\end{array}$ & $\begin{array}{l}\text { Weight } \\
\text { (kgf) }\end{array}$ & Price (US\$/kg) & $\begin{array}{l}\text { Component } \\
\text { cost (US\$) }\end{array}$ \\
\hline $\mathrm{Al}_{2} \mathrm{O}_{3}{ }^{20}$ & 225 & 3.3 & 0.743 & 2.18 & 1.62 \\
\hline $\begin{array}{l}\text { Aramid fabric } \\
\text { laminates }^{20}\end{array}$ & 225 & 1.09 & 0.245 & 63.60 & 15.60 \\
\hline $\begin{array}{l}30 \text { vol.\% sisal fiber } \\
\text { epoxy composite }\end{array}$ & 225 & 1.15 & 0.259 & 11.54 & 2.98 \\
\hline $\begin{array}{l}30 \text { vol. } \% \text { sisal fiber } \\
\text { polyester composite }\end{array}$ & 225 & 1.15 & 0.259 & 3.09 & 0.801 \\
\hline $\begin{array}{l}5052 \mathrm{H} 34 \text { aluminum } \\
\text { sheet }^{20}\end{array}$ & 112.5 & 2.66 & 0.299 & 9.89 & 2.96 \\
\hline \multicolumn{2}{|c|}{ Total weight with aramid (kgf) } & 1.287 & \multicolumn{2}{|c|}{ Total cost with aramid (US\$) } & 20.18 \\
\hline \multicolumn{2}{|c|}{ Total weight with sisal fiber epoxy composite (kgf) } & 1.301 & \multicolumn{2}{|c|}{$\begin{array}{l}\text { Total cost with sisal fiber epoxy composite } \\
\text { (US\$) }\end{array}$} & 7.56 \\
\hline \multicolumn{2}{|c|}{ Total weight with sisal fiber polyester composite (kgf) } & 1.301 & \multicolumn{2}{|c|}{$\begin{array}{l}\text { Total weight with sisal fiber polyester } \\
\text { composite (US\$) }\end{array}$} & 5.381 \\
\hline \multicolumn{2}{|c|}{$\begin{array}{l}\text { Decrease in weight by using sisal fiber polyester } \\
\text { composite instead of aramid }\end{array}$} & $-1.07 \%$ & \multicolumn{2}{|c|}{$\begin{array}{l}\text { Saving in MAS cost by replacing } \\
\text { Kevlar }^{\mathrm{TM}} \text { by the polyester composite }\end{array}$} & $275 \%$ \\
\hline \multicolumn{2}{|c|}{$\begin{array}{l}\text { Decrease in weight by using sisal fiber polyester } \\
\text { composite instead of the epoxy composite }\end{array}$} & $0 \%$ & \multicolumn{2}{|c|}{$\begin{array}{l}\text { Saving in MAS cost by replacing the } \\
\text { epoxy composite by the polyester } \\
\text { composite }\end{array}$} & $40.4 \%$ \\
\hline
\end{tabular}

fiber. This phenomenon was observed in several composite samples, and seems to be a major mechanism of failure. Actually, delamination is expected, since it is known that continuous and aligned fiber composites have a weak direction (transverse), when the load is applied perpendicular to the fiber axis ${ }^{19}$. In the 10 vol. \% composite, the delamination was more severe, Fig. 3b, and the ballistic impact was sufficient to break composite in two pieces. From all of these reasons, the neat polyester resin and the 10 vol. \% composite were not considered adequate to compose the MAS second layer for multi-hit protection ${ }^{17}$.

Through the Weibull statistical analysis, applied to the depth of indentation values, it was possible to obtain additional information about the 20 and 30 vol. \% sisal fiber reinforced polyester composites in the MAS. This analysis was not performed for the $0 \%$ and $10 \%$ composite specimens, since they did not have a satisfactory result in the previous test (loss of integrity on the impact). Table 3 presents corresponding calculated Weibull parameters for the 20 and $30 \%$ composites MAS. The high correlation coefficient $\left(\mathrm{R}^{2}\right)$ values indicate that just a set of failure mechanisms are occurring in both MAS, and this does not change in the observed indentation ranges. In other words, the variability of depth of indentation values within the groups was purely statistical. Indeed, the distribution of probabilities follows a Weibull distribution with high accuracy, 96.42 and $91.99 \%$, for the 20 and 30 vol. \% composites. Moreover, the $\beta$ parameter shows that the 30 vol. $\%$ composite displays more homogeneous results $(\beta=7.357)$ than the $20 \%$ MAS $(\beta=6.969)$. The $\theta$ parameter indicates that the value of indentation for the $30 \mathrm{vol} . \%$ MAS $(\theta=23.00)$ is slightly better than that for $20 \mathrm{vol} \%$ MAS $(\theta=27.63)$. Figure 5 shows the distribution of probabilities for the depths of indentation of both MAS. Although the distribution parameters are different, a large intersection area can be observed, indicating statistical equivalence.

The results of the ballistic tests performed in the MAS components are shown in Table 4. As expected, the ceramic layer absorbs a significantly higher amount of the projectile's energy in comparison with the other tested materials. Apart of the ceramic, evaluating the other intermediate materials, 
the difference is small, and can be considered irrelevant, considering the dispersion of data. A hypothesis test such as analysis of variance applied to the absorbed energy of the materials in Table 4 (excluding the ceramic) confirms this similarity, resulting in a p-value of 0.6453 , which is larger than the level of significance 0.05 (all data are statistically equal).

The advantage of the sisal fiber reinforced composites relative to aramid emerges when considering the materials cost. Table 5 presents a complete economical and weight analysis of the different MAS investigated as well as that in previously study ${ }^{11}$. Approximately $275 \%$ in cost could be saved by replacing aramid laminates by polyester composites in the intermediate layer of the MAS. Relative to the previously studied epoxy composite ${ }^{11}$, the present polyester matrix has the advantage of being almost 3 times cheaper, being sold in the local market for US\$4.30 per kg, while an epoxy resin costs US\$11.54 per $\mathrm{kg}$. In this table it is important to notice that, although the MAS weight is practically the same, the cost of MAS with $30 \mathrm{vol}$. \% sisal fiber-reinforced composite as second layer is much lower. Above all, regarding ballistic performance, weight and cost, the 30 vol.\% sisal fiber composite can be considered one of the most advantageous material for the second layer studied so far.

\section{Conclusion}

- $\quad$ Multilayered armor systems (MAS) using neat polyester as well as, 10, 20 and 30 vol. \% sisal fiber-reinforced polyester were considered equally efficient for the protection against $7.62 \mathrm{~mm}$ caliber ammunition, based on the NIJ 0101.06 criteria based on the depth of indentation in the clay witness (single-hit protection).

- The loss of physical integrity of both the neat polyester resin and the 10 vol. \% sisal fiber polyester composite makes them unsuitable to be used as second layer of a MAS in multi-hit protection.

- The fracture mechanisms of the composites identified the importance of macroscopic delamination and microscopic capture of ceramic and projectile fragments.

- Among all the sisal fiber-reinforced polyester composites studied in the present work, that with 30 vol. \% presented the best results, in terms of trauma prevention and physical integrity after the impact. Therefore, it was considered the most suitable material to be considered as MAS second layer. This is also corroborated by an economical advantage for a complete MAS with 30 vol.\% sisal fiber polyester composite in comparison with more expensive ones with Kevlar ${ }^{\mathrm{TM}}$ or sisal fiberreinforced epoxy composite.

\section{Acknowledgements}

The authors of the present work wish to thank the Brazilian supporting agencies CAPES, CNPq and FAPERJ for the funding, and the CAEx for performing the ballistic tests.

\section{References}

1. Cooper G, Gotts P. Ballistic Protection. In: Mahoney PF, Ryan JM, Brooks AJ, Schwab CW, eds. Ballistic Trauma: A Practical Guide. $2^{\text {nd }}$ ed. London: Springer-Verlag; 2005. p. 67-90.

2. Hani ARA, Roslan A, Mariatti J, Maziah M. Body Armor Technology: A Review of Materials, Construction Techniques and Enhancement of Ballistic Energy Absorption. Advanced Materials Research. 2012;488-489:806-812.

3. Medvedovski E. Ballistic performance of armour ceramics: Influence of design and structure. Part 1. Ceramics International. 2010;36(7):2103-2115.

4. Akella K, Naik NK. Composite armour - a review. Journal of the Indian Institute of Science. 2015;95(3):297-312.

5. Shokrieh M, Javadpour GH. Penetration analysis of a projectile in ceramic composite armor. Composite Structures. 2008;82(2):269276 .

6. Monteiro SN, Lima EP Jr., Louro LHL, Silva LC, Drelich JW. Unlocking Function of Aramid Fibers in Multilayered Ballistic Armor. Metallurgical and Materials Transactions A. 2014;46(1):37-40.

7. John MJ, Thomas S. Biofibres and biocomposites. Carbohydrate Polymers. 2008;71(3):343-364.

8. Monteiro SN, Milanezi TL, Louro LHL, Lima EP Jr., Braga FO, Gomes AV, et al. Novel ballistic ramie fabric composite competing with Kevlar $^{\mathrm{TM}}$ fabric in multilayered armor. Materials \& Design. 2016;96:263-269.

9. Cruz RB, Lima EP Jr., Monteiro SN, Louro LHL. Giant Bamboo Fiber Reinforced Epoxy Composite in Multilayered Ballistic Armor. Materials Research . 2015;18(Suppl. 2):70-75.

10. Luz FS, Lima EP Jr., Louro LHL, Monteiro SN. Ballistic Test of Multilayered Armor with Intermediate Epoxy Composite Reinforced with Jute Fabric. Materials Research. 2015;18(Suppl 2):170-177.

11. Rohen LA, Margem FM, Monteiro SN, Vieira CMF, Araújo BM, Lima ES. Ballistic Efficiency of an Individual Epoxy Composite Reinforced with Sisal Fibers in Multilayered Armor. Materials Research. 2015;18(Suppl. 2):55-62.

12. Monteiro SN, Candido VS, Braga FO, Bolzan LT, Weber RP, Drelich JW. Sugarcane bagasse waste in composites for multilayered armor. European Polymer Journal. 2016;78:173185 .

13. Meyers MA. Dynamic Behavior of Materials. New York: John Wiley \& Sons; 1994.

14. Cheeseman BA, Bogetti TA. Ballistic impact into fabric and compliant composite laminates. Composite Structures. 2003;61(1-2):161-173. 
15. Lee BL, Song JW, Ward JE. Failure of Spectra ${ }^{\circledR}$ Polyethylene Fiber Reinforced Composites under Ballistic Impact Loading. Journal of Composite Materials. 1994;28(13):1202-1226.

16. Monteiro SN, Lopes FPD, Barbosa APB, Bevitori AB, Silva ILA, Costa LL. Natural Lignocelullosic Fibers as Engineering Materials - An Overview. Metallurgical and Materials Transactions A. 2011;42:2963-2974.

17. National Institute of Justice. Standards - 0101.06: Ballistic Resistance of Body Armor. Washington: National Institute of Justice; 2008.
18. Monteiro SN, Louro LHL, Trindade W, Elias CN, Ferreira CL, Lima ES, et al. Natural Curaua Fiber-Reinforced Composites in Multilayered Armor. Metallurgical and Materials Transactions A. 2015;46(10):4567-4577.

19. Callister WD Jr., Rethwisch DG. Materials Science and Engineering: An Introduction. $8^{\text {th }}$ ed. Hoboken: John Wiley \& Sons; 2012.

20. Monteiro SN, Braga FO, Lima EP, Louro LHL, Drelich JW. Promising curaua fiber-reinforced polyester composite for high-impact ballistic multilayered armor. Polymer Engineering \& Science. 2017;57(9):947-954. 